\title{
Triazole Diglycolamide Cavitand for Lanthanide Extraction.
}

\author{
M. Wehbie ${ }^{a, b}$, G. Arracharta, I. Karaméb ${ }^{\text {, L. Ghannam }}$, and S. Pellet-Rostaing ${ }^{a^{*}}$. \\ a Institut de Chimie Séparative de Marcoule, ICSM, UMR 5257-CEA/CNRS/UM/ENSCM Site de Marcoule, Bât 426, \\ BP 17171, 30207 Bagnols sur Cèze Cedex, stephane.pellet-rostaing@cea.fr \\ b Laboratory of Organometallic Catalysis and Coordination Chemistry, Department of Chemistry, Lebanese \\ University, Faculty of Sciences I, Beirut, Lebanon.
}

\begin{abstract}
Click chemistry, which relies on the efficiency of the copper (I)-catalyzed azide-alkyne cycloaddition, was used to link four diglycolamide (DGA) moieties to a resorcinarene platform leading to a specific tetra-DGA-resorcinarene ligand (c-methylcalix(4)methylresorcinarene-4triazole-dioctyldiglycolamide denoted CR4-Tz-DODGA). The extraction ability of this ligand was studied in a mixture of toluene / iso-octanol $(90 / 10, \mathrm{v} / \mathrm{v}$ ) toward rare earth elements (REE) at different nitric acid concentrations, ranging from 1 to $5 \mathrm{M}$. The results show the efficient extractability of and selectivity towards heavy REEs. The stoichiometry of the extraction was established by the slope analysis method and an extraction mechanism was proposed based on estimates of the thermodynamic parameters. From the extraction behavior of the tetraDGA-resorcinarene ligand, we present the possibility for the extraction and separation of dysprosium from used permanent magnets.
\end{abstract}

Keywords: DGA, Resorcinarene, Selective ionic separation, Lanthanide

\section{Introduction}

Rare earth elements (REEs) comprise the family of lanthanides including scandium and yttrium. Due to their similar chemical properties, REEs are rarely separated from each other.[1] These elements have a wide range of technical applications, and the forecasted average annual demand growth of REEs is stated to increase to more than $8 \%$ every year by 2020.[2] In contrast to increased REE demand, the supply of such materials is currently experiencing a shortage and as an alternative to increased mining operations, recycling can be used to reduce the stress on the rare earth supply.[3] In addition, REEs are significant byproducts of fission reactions as they represent approximately $40 \%$ of the fission product mass and include measurable amounts of all lanthanides. The separation of lanthanides from actinides can be a challenging obstacle in effective waste management.[4]

Several methods have been investigated for the recovery of REEs by membrane filtration,[5] solid-liquid separation using chelating organic resins,[6] as well as organicinorganic materials.[7] 
Solvent extraction has long been used for the recovery and the separation of REEs, which is usually accomplished by using phospho-compounds in organic solvents and also in ionic liquid diluents.[9,10] Among many other extractants well-known in the field of metals extraction and nuclear fuel reprocessing, diglycolamides have gained importance within the field since first reported by Stephan and co-workers in 1991. [11,12]

Diglycolamides (DGAs) have favorable characteristics as they are tridentate O-donating ligands, which allows them to form stable complexes with lanthanides and actinides. DGAs consist of $\mathrm{C}, \mathrm{H}, \mathrm{N}$, and $\mathrm{O}$ atoms and can be incinerated completely to form gaseous products after utilization.[13-16] Though several DGA compounds have been studied, the effect of DGA unit preorganization in a macrocyclic platform used in REE extraction has not been examined in detail. The positive effects on the extraction efficiency of ligand preorganization within a platform has been established.[17]

Therefore the advantages preorganization of DGA sites in a calix[4]arene provide have been studied and proven to be far superior to TODGA, with comparable extractions at 100 times lower concentrations and increased efficiency with an increased number of DGA units.[18,19] The number of DGA units and the flexibility provided by spacer lengths is an important parameter in the extraction ability of the ligands. Among different macrocycles, cavitand analogues of C-methylcalix(4)methyl-resorcinarene provides an excellent preorganized platform for the coordination of host systems due to its conformational rigidity, which is assured by the methylene bridge between the hydroxyl groups of two neighboring phenyl rings. Its functionalization can be easily performed making the platform a focus of interest for a wide range of applications, such as being used as host molecules, $[20,21]$ components in liquid crystals,[22] photoresistors,[23] HPLC stationary phases,[24] self-assembled capsules,[25] surfactants, for potential sensor applications,[26] as an antibacterial agent,[27] and with biomolecules.[28]

Click chemistry, developed by Sharpless and co-workers,[29] is widely utilized in various fields, including organic,[30] medicinal,[31] materials,[32] and biological chemistry. [33] Its popularity stems from its simplicity, high conversion, the absence of side product formation, and mild reaction conditions. Therefore, copper-catalyzed azide-alkyne cycloaddition (CUAAC) is one of the most useful reactions for the covalent attachment of appropriate functional groups.

A cavitand containing azide groups was synthesized and engaged in a click reaction with the terminal alkyne of a DGA moiety. The success of the functionalization was monitored by FT-IR, NMR and MS analysis. The performance of the resulting Tetrakis(4triazolomethyldioctyldiglycolamide)-tetramethyl cavitand (CR4-Tz-DODGA, Figure 1) in solvent extraction experiments was evaluated for REEs under acidic feed conditions. The stoichiometry of the complexes and the extraction mechanism involved are discussed with regards to the extraction of the REEs. Finally, the ligand exhibited highly favorable separation behavior of REEs from a simulated solution of permanent magnets. 


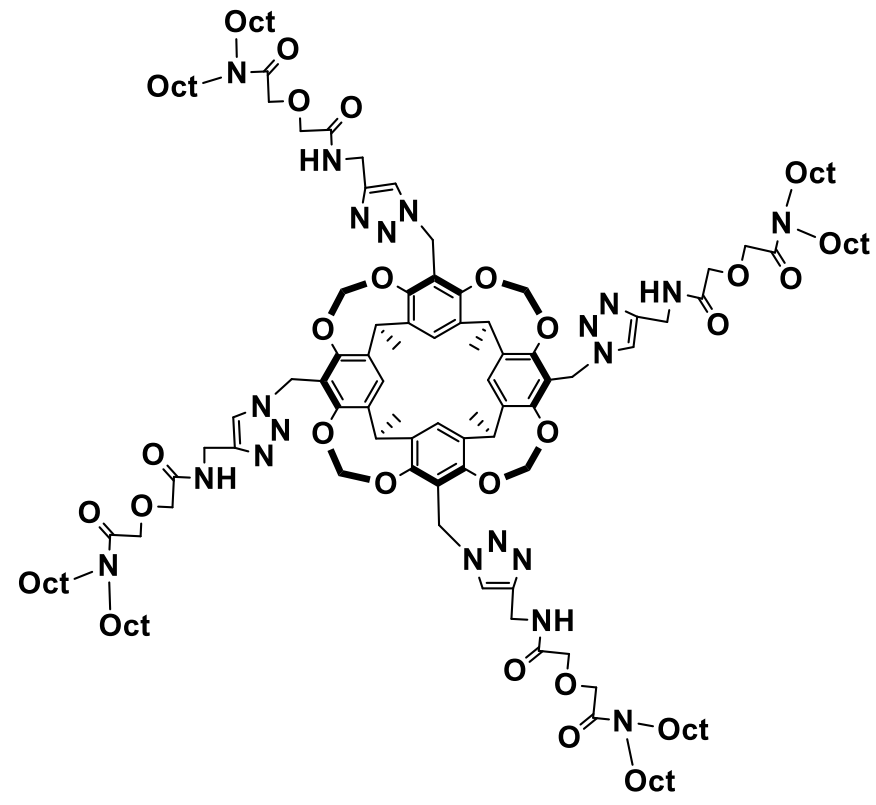

Figure 1: Structure of CR4-TZ-DODGA

\section{Methods and materials}

\subsection{Chemicals and analysis}

Chemicals (analytically pure) were purchased from Sigma-Aldrich or Alfa Aesar and were used without further purification. Anhydrous solvents were purchased from Acros (AcroSeal ${ }^{\circledR}$ ). Reactions were monitored by thin layer chromatography (Merck TLC Silica Gel 60 F254).

Flash chromatography was performed using a combiflash Agilent Intelliflash 971-FP. NMR analyses were performed on a Bruker 400 ultrashield VS spectrometer. Chemical shifts are reported in ppm using the solvent $\left(\mathrm{CDCl}_{3}: 7.26 \mathrm{ppm}\right.$ for ${ }^{1} \mathrm{H} ; 77.16 \mathrm{ppm}$ for $\left.{ }^{13} \mathrm{C}\right)$ as an internal reference. Metal concentrations were determined using a spectro ARCOS ICPAES spectrometer. Fourier transform infrared (FTIR) measurements were performed on a Perkin Elmer Spectrum 100 instrument in ATR (Attenuated Total Reflection) mode. The measured range was from $400 \mathrm{~cm}^{-1}$ to $4000 \mathrm{~cm}^{-1}$ with a $4 \mathrm{~cm}^{-1}$ beam resolution. Background acquisition was conducted prior to measurement. ESI-MS was performed on a Flexar SQ $300 \mathrm{MS}$ instrument.

\subsection{Synthesis}

Preparation of Propargyl-DODGA 2

$1.62 \mathrm{~g}$ of 2-(2-(dioctylamino)-2-oxoethoxy) acetic acid 1,[34] (4.54 mmol) and $0.675 \mathrm{~g}$ of hydroxyl benzotriazole $(4.99 \mathrm{mmol})$ were poured into $30 \mathrm{ml}$ chloroform at $0{ }^{\circ} \mathrm{C}$. The obtained suspension was stirred for 30 minutes at room temperature, then $0.25 \mathrm{~g}$ of propargyl amine 
(4.54 mmol) and $1.03 \mathrm{~g}$ of dicyclohexylcarbodiimide DCC (4.99 mmol) were added, and the resulting suspension was stirred for two days. After filtration and evaporation of the solvent, the crude product was purified using column chromatography $\left(\mathrm{SiO}_{2}\right.$, dichloromethane/methanol 5\%), affording compound 2 as a brown dense oil with a yield $=72$ \%. ${ }^{1} \mathrm{H}$ NMR $\left(400 \mathrm{MHz}, \mathrm{CDCl}_{3}\right) \delta$ [ppm]: $0.89\left(\mathrm{~m}, 6 \mathrm{H}, \mathrm{CH}_{2}-\mathrm{CH}_{3}\right), 1.29\left(\mathrm{~m}, 2 \mathrm{H},-\mathrm{NCH}_{2}-\mathrm{CH}_{2}-\mathrm{CH}_{3}\right)$, $1.54\left(\mathrm{~m}, \mathrm{H}, \mathrm{J}=7.2 \mathrm{~Hz}, \mathrm{NH}-\mathrm{CH}_{2}-\mathrm{CH}_{2}\right), 2.21(\mathrm{t}, 1 \mathrm{H}, \mathrm{J}=2.4 \mathrm{~Hz}, \mathrm{CH}), 3.1$ (t, 2H, 7.6 Hz, N-CH 2 -heptyl), 3.23 (t, $2 \mathrm{H}, 7.6 \mathrm{~Hz}, \mathrm{~N}-\mathrm{CH}_{2}$-heptyl), 4.09 (d, $2 \mathrm{H}, \mathrm{J}=2.8 \mathrm{~Hz}, \mathrm{~N}-\mathrm{CH}_{2}$ ) 4.1 (s, 2H, CO-CH2 $-\mathrm{CO}$ ), 4.25 (s, $\left.2 \mathrm{H}, \mathrm{CO}-\mathrm{CH}_{2}-\mathrm{CO}\right), 8.2(\mathrm{~s}, 1 \mathrm{H}, \mathrm{NH}-\mathrm{C}=\mathrm{O}) .{ }^{13} \mathrm{C} \mathrm{NMR}\left(400 \mathrm{MHz}, \mathrm{CDCl}_{3}\right) \delta[\mathrm{ppm}]: 14.1,22.6,26.9,27.0$, $27.6\left(\mathrm{NH}-\mathrm{CH}_{2}\right), 28.5,28.9,29.2,29.2,29.3,29.4,31.7,31.8,46.2,46.8\left(-\mathrm{CH}_{2}-\right), 71.2(\equiv \mathrm{CH}), 69.6$ \& $71.8\left(-\mathrm{CH}_{2} \mathrm{O}-\right), 79.5(-\mathrm{C} \equiv), 168.1,169.4(\mathrm{C}=\mathrm{O})$.

Preparation of cavitand $\mathbf{3}$

Cavitand $\mathbf{3}$ was prepared as described by Cram et al, and identified by comparison of its ${ }^{1} \mathrm{H}$ NMR spectrum with literature values. [35] 3 was obtained as dark yellow powder (yield $88 \%$ ). ${ }^{1} \mathrm{H}$ NMR (400 MHz, DMSO) $\delta$ [ppm]: $1.70\left(\mathrm{~d}, 12 \mathrm{H}, \mathrm{CH}_{3} \mathrm{CH}\right.$ ), $2.00\left(\mathrm{~s}, 12 \mathrm{H}, \mathrm{ArCH}_{3}\right), 4.46$ (q.4H, $\left.\mathrm{CH}_{3} \mathrm{CH}\right), 7.41(\mathrm{~s}, 4 \mathrm{H}, \mathrm{ArH}), 8.70(\mathrm{~s}, 8 \mathrm{H}, \mathrm{ArOH}) . \mathrm{m} / \mathrm{z}: 543\left[(\mathrm{M}-\mathrm{H})^{+}\right]$.

Preparation of cavitand 4

Cavitand 4 was prepared by adapting a procedure described in the literature by using dichloromethane instead of bromochloromethane.[27] 4 was obtained as a white powder (yield $84 \%$ ) and the ${ }^{1} \mathrm{H}$ NMR spectrum was in agreement with the previously reported spectrum in the literature.[35],[36], ${ }^{1} \mathrm{H} N M R\left(400 \mathrm{MHz}, \mathrm{CDCl}_{3}\right) \delta[\mathrm{ppm}]: 1.73\left(\mathrm{~d}, 12 \mathrm{H}, \mathrm{CH}_{3} \mathrm{CH}\right)$, $2.00\left(\mathrm{~s}, 12 \mathrm{H}, \mathrm{ArCH}_{3}\right), 4.29\left(\mathrm{~d}, 4 \mathrm{H}\right.$, inner of $\left.\mathrm{OCH}_{2} \mathrm{O}\right), 5.20\left(\mathrm{q}, 4 \mathrm{H}, \mathrm{CH}_{3} \mathrm{CH}\right), 5.92(\mathrm{~d}, 4 \mathrm{H}$, outer of $\left.\mathrm{OCH}_{2} \mathrm{O}\right), 7.14(\mathrm{~s}, 4 \mathrm{H}, \mathrm{ArH})$.

Preparation of cavitand $\mathbf{5}$

Cavitand $\mathbf{5}$ was prepared using a procedure described by Moran et al. $\mathbf{5}$ was obtained as a white powder (yield $90 \%) .{ }^{1} \mathrm{H} N M R\left(400 \mathrm{MHz}, \mathrm{CDCl}_{3}\right) \delta$ [ppm]: 1.75 (d, $12 \mathrm{H}, \mathrm{J}=7.4 \mathrm{~Hz}, \mathrm{CHCH}_{3}$ ), $4.42\left(\mathrm{~s}, 8 \mathrm{H}, \mathrm{CH}_{2} \mathrm{Br}\right), 4.57\left(\mathrm{~d}, 4 \mathrm{H}, \mathrm{J}=7.0 \mathrm{~Hz}\right.$, inner $\left.\mathrm{OCH}_{2} \mathrm{O}\right), 5.02(\mathrm{q}, 4 \mathrm{H}, \mathrm{J}=7.4 \mathrm{~Hz}, \mathrm{CH}), 6.04(\mathrm{~d}, 4$ $\mathrm{H}, \mathrm{J}=7.0 \mathrm{~Hz}$, outer $\left.\mathrm{OCH}_{2} \mathrm{O}\right), 7.26(\mathrm{~s}, 4 \mathrm{H}, \mathrm{ArH})$.

Preparation of cavitand 6

In a round bottomed flask, cavitand $5(2 \mathrm{~g}, 2.4 \mathrm{mmol})$ was dissolved in $60 \mathrm{ml}$ of acetone. Sodium azide $(2 \mathrm{~g}, 30.76 \mathrm{mmol})$ was added to the solution. The mixture was stirred under reflux for $4 \mathrm{~h}$. The mixture was filtered over Celite and washed with acetone. The collected solution was evaporated using a rotary evaporator and the residue was purified using column chromatography ( $\mathrm{SiO}_{2}$, ethyl acetate /cyclohexane, 65/35). Cavitand 6 was obtained as a white powder (yield $85 \%) .{ }^{1} \mathrm{H} \mathrm{NMR} \mathrm{(400MHz}, \mathrm{CDCl}_{3}$ ) $\delta[\mathrm{ppm}]: 1.75$ (d, $12 \mathrm{H}, J=7.4 \mathrm{~Hz}, \mathrm{CHCH}_{3}$ ), 4.3 (s, $\left.8 \mathrm{H}, \mathrm{CH}_{2} \mathrm{~N}_{3}\right), 4.42\left(\mathrm{~d}, 4 \mathrm{H}, \mathrm{J}=7.0 \mathrm{~Hz}\right.$, inner $\left.\mathrm{OCH}_{2} \mathrm{O}\right), 5.0\left(\mathrm{q}, 4 \mathrm{H}, \mathrm{J}=7.4 \mathrm{~Hz}, \mathrm{CH}_{3} \mathrm{CH}\right), 6.0(\mathrm{~d}, 4 \mathrm{H}, \mathrm{J}=7.0$ $\mathrm{Hz}$, outer $\left.\mathrm{OCH}_{2} \mathrm{O}\right), 7.3(\mathrm{~s}, 4 \mathrm{H}, \mathrm{ArH}) ;{ }^{13} \mathrm{C}-\mathrm{NMR}(\mathrm{CDCl} 3,400 \mathrm{MHz}), \delta[\mathrm{ppm}]: 153.3(\mathrm{Ar}-\mathrm{Cq}), 139.1$ (Ar-Cq), 122.2 (Ar-Cq), 120.3 (Ar-H), 99.7 (Ar-CH $-\mathrm{Cr}$ ), 45.1 ( $\left.\mathrm{Ar}-\mathrm{CH}_{2}-\mathrm{N} 3\right), 31.2$ (Ar-CH-Ar), 16.1 (CH3). (m/z): 835 [(M+Na) $\left.)^{+}\right]$; FT-IR (ATR crystal): $v\left(\mathrm{~cm}^{-1}\right) 2090$ $\left(v_{\text {as }}-\mathrm{N}_{3}\right)$. 


\section{Preparation of cavitand 7}

Azide 6 (1 eq, $0.2 \mathrm{~g}, 0.246 \mathrm{mmol}$ ) was dissolved in a mixture of THF/ $\mathrm{H}_{2} \mathrm{O}(2: 1 \mathrm{v} / \mathrm{v} 5 \mathrm{ml}) .2$ (4 eq, $0.388 \mathrm{~g}, 0.984 \mathrm{mmol}), \mathrm{CuSO}_{4} .5 \mathrm{H}_{2} \mathrm{O}(0.4 \mathrm{eq}, 0.025 \mathrm{~g}, 0.098 \mathrm{mmol})$ and sodium ascorbate $(0.8$ eq, $0.039 \mathrm{~g}, 0.197 \mathrm{mmol}$ ) were added to the solution. The resulting mixture was stirred at $50^{\circ}$ $\mathrm{C}$ for $24 \mathrm{~h}$, then THF was evaporated and the resulting precipitate was dissolved in $30 \mathrm{ml} \mathrm{DCM}$ and washed 3 times with $30 \mathrm{ml}$ of $25 \%$ Ammonia. The organic layer was dried over anhydrous $\mathrm{Na}_{2} \mathrm{SO}_{4}$. The solvent was evaporated and the crude product was purified using flash chromatography $\left(\mathrm{SiO}_{2}\right.$, dichloromethane/methanol 5\%) to afford the pure product (yield 65 \%). ${ }^{1} \mathrm{H}$ NMR (400MHz, CDCl 3 ) $\delta[p p m]: 0.88\left(\mathrm{t}, 24 \mathrm{H}, \mathrm{J}=6.4 \mathrm{~Hz}, \mathrm{CH}_{2}-\mathrm{CH}_{3}\right), 1.29\left(\mathrm{~m}, 80 \mathrm{H},-\mathrm{CH}_{2}-\right.$ $\left.\left(\mathrm{CH}_{2}\right)_{40}-\mathrm{CH}_{3}\right), 1.54$ (p, 16H, J=7.2 Hz, NH-CH$-\mathrm{CH}_{2}$ ), 1.77 (d, $\left.12 \mathrm{H}, \mathrm{J}=7.2 \mathrm{~Hz}, \mathrm{CHCH}_{3}\right), 3.1$ (t, 8H, $7.2 \mathrm{~Hz}, \mathrm{~N}-\mathrm{CH}_{2}$-heptyl), 3.33 (t, 8H, $7.2 \mathrm{~Hz}, \mathrm{~N}-\mathrm{CH}_{2}$-heptyl), 4.1 (s, 8H, CO-CH2-O), 4.24 (s, 8H, O$\left.\mathrm{CH}_{2}-\mathrm{CO}\right), 4.15\left(\mathrm{~m}, 4 \mathrm{H}\right.$, inner $\left.\mathrm{OCH}_{2} \mathrm{O}\right), 4.55\left(\mathrm{~s}, 4 \mathrm{H}, \mathrm{Tz}-\mathrm{CH}_{2}-\mathrm{NH}\right), 4.98$ (q, $\left.4 \mathrm{H}, \mathrm{J}=7.4 \mathrm{~Hz}, \mathrm{CH}-\mathrm{CH}_{3}\right)$, $5.27\left(\mathrm{~s}, 4 \mathrm{H}, \mathrm{Ar}-\mathrm{CH}_{2}-\mathrm{Tz}\right), 5.82\left(\mathrm{~m}, 4 \mathrm{H}, \mathrm{J}=6.8 \mathrm{~Hz}\right.$, outer $\left.\mathrm{OCH}_{2} \mathrm{O}\right), 7.2(\mathrm{~s}, 4 \mathrm{H}, \mathrm{ArH}), 7.6(\mathrm{~s}, 4 \mathrm{H} \mathrm{TzCH})$, $8.09(\mathrm{~s}, 4 \mathrm{H}, \mathrm{NH}) ;{ }^{13} \mathrm{C} \mathrm{NMR}\left(400 \mathrm{MHz}, \mathrm{CDCl}_{3}\right) \delta[\mathrm{ppm}]: 14.1,16.2,22.6,26.9,27.1,27.7,28.9$, 29.2, 29.3, 29.4, 31.2, 31.8, 31.8, 34.6 (Ar- $\left.\mathrm{CH}-\mathrm{CH}_{3}\right), 44.0,46.2,46.8,69.5,71.5,99.7\left(\mathrm{O}-\mathrm{CH}_{2-}\right.$ O), $120.8(\mathrm{Ar}-\mathrm{CH}), 122.8$ (TzCH), 129.7, 138.9, 144.7 (TzC), 153.4, 168.1(CO-N), 169.7 (CO-N); $(\mathrm{m} / \mathrm{z}): 2413\left[(\mathrm{M}+\mathrm{Na})^{+}\right]$; FT-IR (ATR crystal): $v\left(\mathrm{~cm}^{-1}\right) 1643(v \mathrm{C}=\mathrm{O})$.

\subsection{Extraction experiments}

Rare earth element (REE) stock solutions were prepared at the desired acidity from $1000 \mathrm{mg} \cdot \mathrm{L}^{-}$ ${ }^{1}$ ICP standard (in $1 \% \mathrm{HNO}_{3}$ ) of lanthanum, europium and ytterbium. A synthetic solution mimicking the leaching of magnets was prepared from $1000 \mathrm{mg} \cdot \mathrm{L}^{-1} \mathrm{ICP}$ standard (in $1 \% \mathrm{HNO}_{3}$ ) of neodymium, dysprosium, iron and boron. The desired concentrations were prepared by dilution using ultrapure water (MilliQ, Millipore, $>18 \mathrm{M} \Omega \mathrm{cm}^{-1}$ ) and the acidity was adjusted with nitric acid.

Organic solutions of CR4-Tz-DODGA at varying concentrations were prepared in a mixture of toluene / iso-octanol (90/10 v/v). Iso-octanol was used as a phase modifier. Turbid solutions were obtained when solutions without the phase modifier were mixed with $>2 \mathrm{M}$ nitric acid.

Organic phases were pre-equilibrated with an aqueous phase at the same acidity as the extraction step without REE cations. The pre-equilibrated organic phases were then mixed with an equal volume of an aqueous acidic stock solution of REEs in a thermostated shaker (Infor-ht ${ }^{\circledR}$ ecotron) at $25^{\circ} \mathrm{C}$ for one hour at $400 \mathrm{rpm}$. Phases were separated after centrifugation at 4000 rpm for 30 minutes (sigma 3-16 PK). After centrifugation, the separated aqueous phases were subjected to ICP-AES analysis to determine the distribution ratio $\left(D_{M}\right)$, which is the ratio of the total concentration of metal $M$ in the organic phase to the total concentration of the same metal in the aqueous phase, i.e., $D_{M}=\left[M_{\text {org }}\right] /\left[M_{a q}\right]$. The suitability of the extractant is also associated with the separation factors $\mathrm{SF}_{\mathrm{M} 1} / \mathrm{M}_{2}$ that is the ratio of the distribution ratios $D_{M 1}$ and $D_{M 2}\left(S F_{M 1} / M_{2}=D_{M 1} / D_{M 2}\right)$, and finally describes the selectivity for $\mathrm{M} 1$ over $\mathrm{M} 2$. The experiments were carried out in duplicate 
with a precision of $\pm 5 \%$. The full set of solvent extraction data of the lanthanide cations ( $\mathrm{La}^{3+}$, $\mathrm{Eu}^{3+}$, and $\mathrm{Yb}^{3+}$ ) are summarized in Table $\mathrm{S} 1$ in the supporting information.

\section{Results and discussion}

\subsection{Synthesis and characterizations of CR4-Tz-DODGA}

CR4-Tz-DODGA was synthesized via a general synthetic route in six steps according to scheme 1. The "clickable DGA" (2) was prepared by amide coupling of propargylamine with DODGA 1 using DCC as the coupling agent in the presence of HOBt.[34]

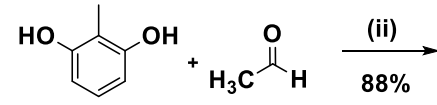

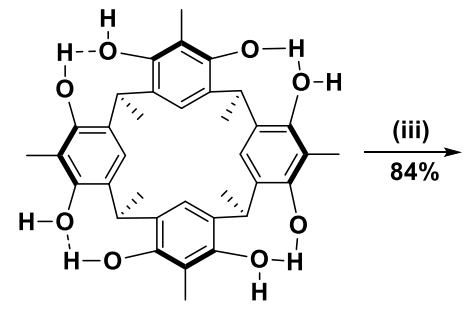

(3)

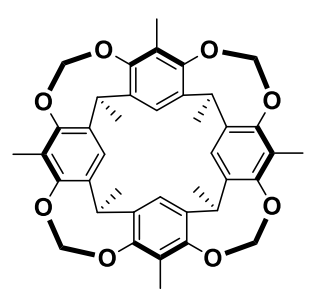

(4)

(iv) $90 \%$

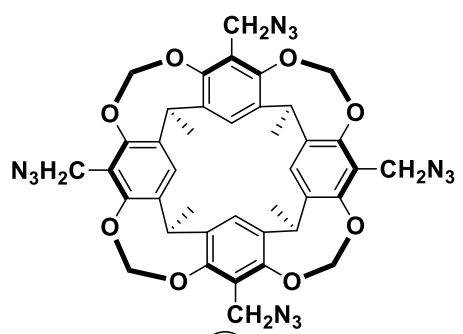

(6)

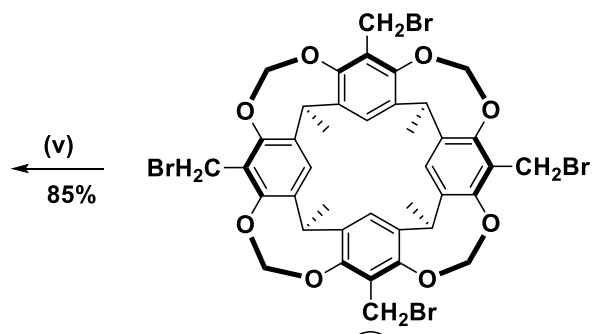

(5)

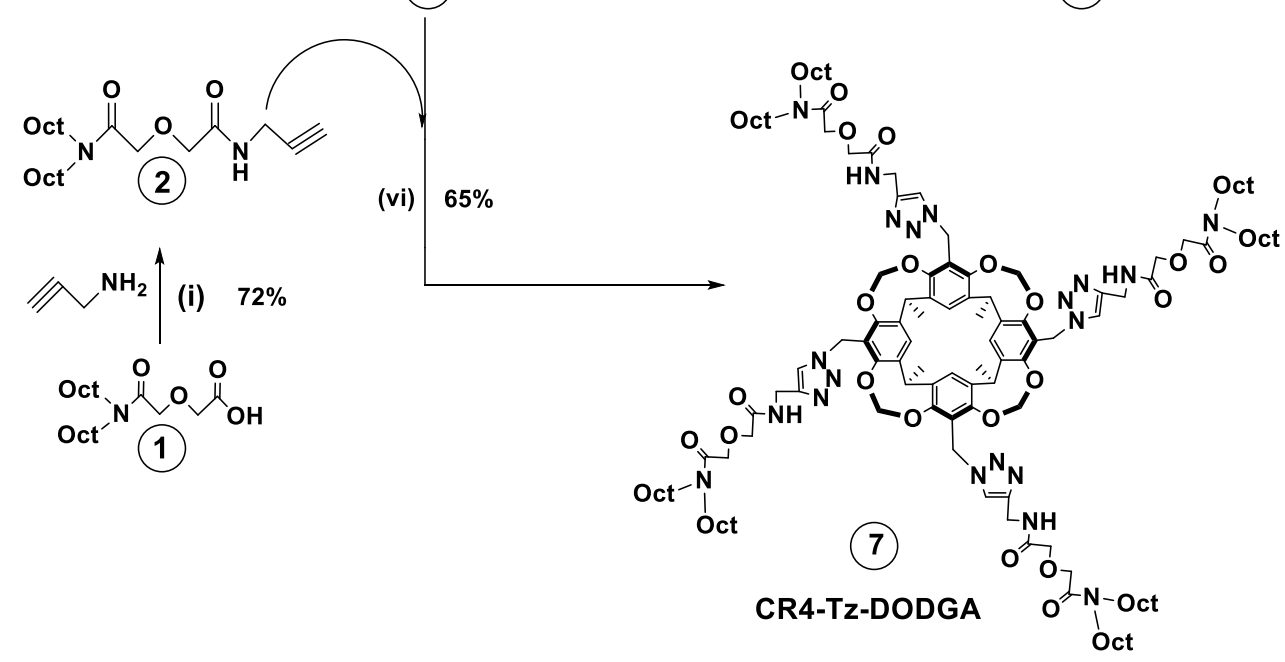

Scheme 1: Synthetic route for CR4-Tz-DODGA

(i) $\mathrm{DCC}+\mathrm{HOBT} / \mathrm{CHCl}_{3}$ (ii) $\mathrm{H}_{2} \mathrm{O}-\mathrm{EtOH} / \mathrm{HCl}, 80^{\circ} \mathrm{C}$; (iii) $\mathrm{CH}_{2} \mathrm{Cl}_{2} / \mathrm{K}_{2} \mathrm{CO}_{3} / \mathrm{DMF}-70^{\circ} \mathrm{C}$; (iv) NBS-Benzoyl peroxide/CCl $\mathrm{Cl}_{4}$ eflux; (v) $\mathrm{NaN}_{3} /$ Acetone, $60^{\circ} \mathrm{C}$; (vi) $\mathrm{CuSO}_{4}, 5 \mathrm{H}_{2} \mathrm{O}$, sodium ascorbate/THF- $\mathrm{H}_{2} \mathrm{O}$.

The selective and efficient introduction of azido groups to an appropriate position on the cavitand was performed in three steps. Cavitands $\mathbf{4}$ and $\mathbf{5}$ were prepared according to procedures previously described in the literature.[35,36] Derivative 6 , having azido groups, 
was prepared by nucleophilic substitution of cavitand 5 using $\mathrm{NaN}_{3}$ in acetone. The 'Click' linkage of DGA derivative $\mathbf{2}$ was efficiently accomplished with azido-containing resorcinarene under $\mathrm{Cu}(\mathrm{I})$-catalyzed conditions using $\mathrm{CuSO}_{4} \cdot 5 \mathrm{H}_{2} \mathrm{O}$ /sodium ascorbate as the catalyst. ${ }^{1} \mathrm{H}-\mathrm{NMR}$ spectra of cavitands $\mathbf{6}$ and $\mathbf{7}$ are in accordance with their structures.

The success in the functionalization of the resorcinarene by the DGA unit was monitored by FT-IR, ${ }^{1} \mathrm{H}-\mathrm{NMR},{ }^{13} \mathrm{C}-\mathrm{NMR},{ }^{1} \mathrm{H}-{ }^{1} \mathrm{H}$ COSY, and ${ }^{1} \mathrm{H}-{ }^{13} \mathrm{C}$ HSQC in addition to high resolution mass spectroscopy (see Figures S1 -S5 in the supporting information). The disappearance of the azide stretching vibration at $2090 \mathrm{~cm}^{-1}$ could be observed in the IR spectrum, which indicates the complete conversion of the $\mathrm{N}_{3}$ groups into the triazole functionalities, and the formation of new stretching bands at $1644 \mathrm{~cm}^{-1}$, corresponding to the amide groups of the DGA side arms, was observed (Figure 2).

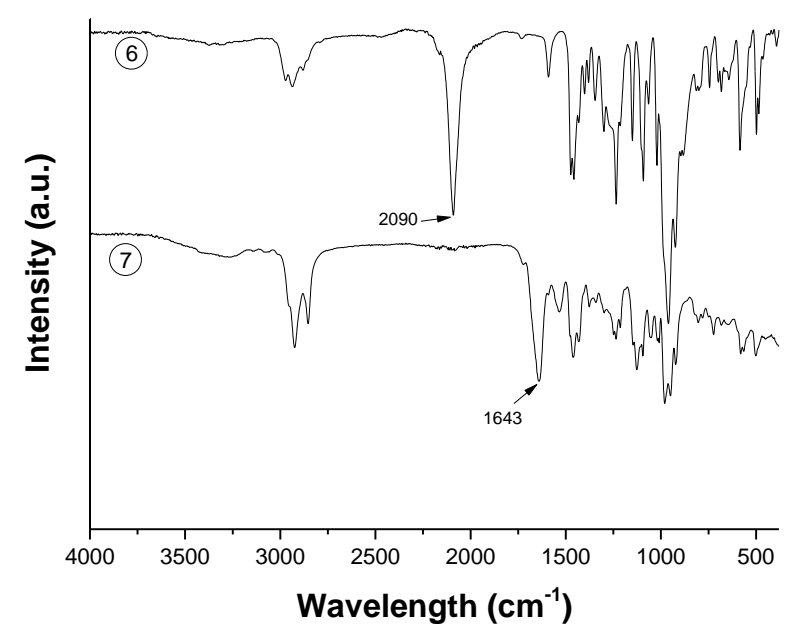

Figure 2: FT-IR spectra: cavitands 6 and 7.

Isolation of the final product was further confirmed by a resonance signal at $7.63 \mathrm{ppm}$ in the ${ }^{1} \mathrm{H}-\mathrm{NMR}$ spectrum (Figure 3a) and two resonance signals at 122.8 and $144.7 \mathrm{ppm}$ in ${ }^{13} \mathrm{C}-\mathrm{NMR}$ spectrum (Figure 3b), characteristic of 1,4-disubstituted 1,2,3-triazoles. In addition, the DGA side arms were identified by the two resonance signals of the methylene groups at 68.8 and $69.1 \mathrm{ppm}$, and two other signals at 168.14 and $169.74 \mathrm{ppm}$ in the ${ }^{13} \mathrm{C}-\mathrm{NMR}$ spectrum, corresponding to the amide carbonyl groups. 

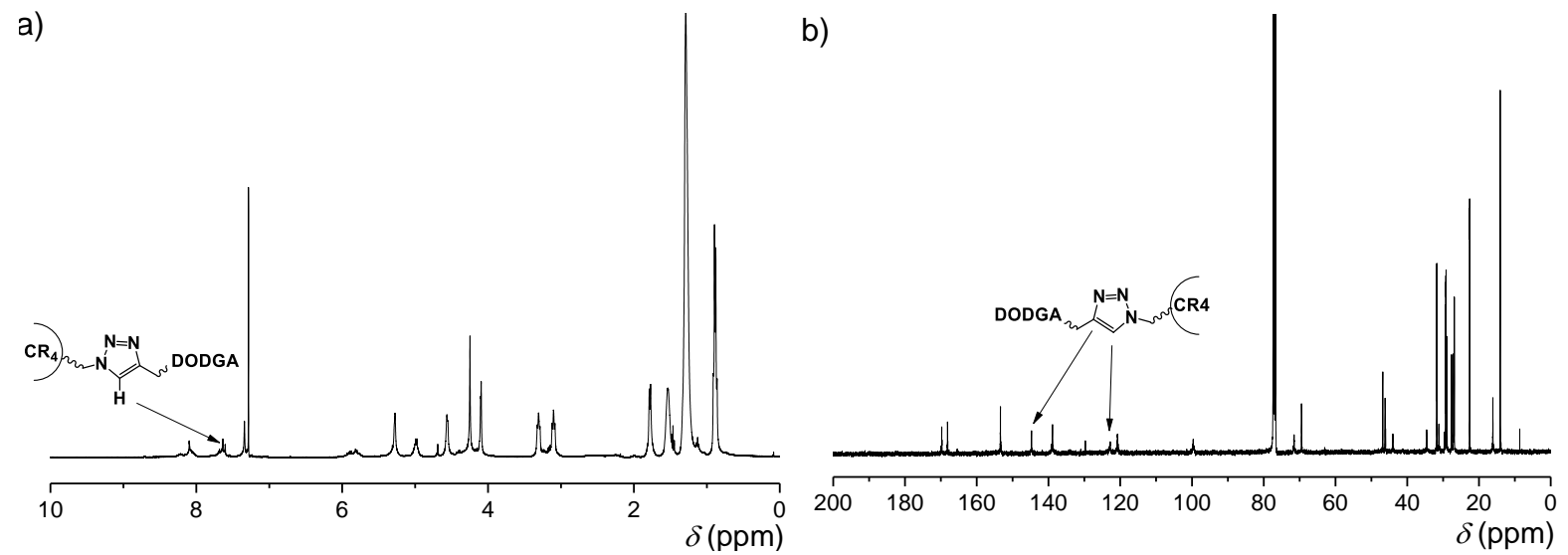

Figure 3: a) ${ }^{1} \mathrm{H}$ and b) ${ }^{13} \mathrm{C} N \mathrm{~N} R$ spectra of Cavitand 7 with characteristic signals to the 1,4disubstituted 1,2,3-triazoles

\subsection{Application in ionic separation}

Solvent extraction was carried out using a CR4-Tz-DODGA solution in a mixture of toluene and iso-octanol (9/1, v/v). The extraction profile was established for La, and Eu as light rare earth elements (LREE) and $\mathrm{Yb}$ as a heavy rare earth element (HREE). The metal to ligand ratios ( $\mathrm{M}$ : L) were varied from $(1: 0.33)$ up to $(1: 5)$. At a $(1: 3)$ ratio, which is a very weak ratio with respect to what has been used for similar platforms,[16] we obtained very interesting results and the ligand was able to extract approximately $97 \%$ of $\mathrm{Yb}$ with a distribution coefficient of 31 (Table 1).

Table 1: Extraction equilibrium constants for La(III), Eu(III), and Yb(III) at $298 \mathrm{~K}$.

\begin{tabular}{|c|c|c|c|c|c|c|c|}
\hline & & \multicolumn{5}{|c|}{ [Ligand] $\mathrm{mM}$} & \multirow{2}{*}{ Av. $\log _{(\text {Kex })}$} \\
\hline & & 0.33 & 1.00 & 2.00 & 3.00 & 5.00 & \\
\hline \multirow{2}{*}{ La } & $\mathrm{D}$ & $<0.01$ & 0.01 & 0.52 & 0.10 & 0.33 & \\
\hline & $\log _{(\text {Kex })}$ & 3.08 & 3.17 & 3.25 & 3.19 & 3.27 & 3.19 \\
\hline \multirow{2}{*}{$\mathrm{Eu}$} & $\mathrm{D}$ & 0.02 & 0.17 & 0.57 & 1.44 & 4.92 & \\
\hline & $\log _{(\text {Kex })}$ & 4.50 & 4.52 & 4.48 & 4.53 & 4.60 & 4.53 \\
\hline \multirow{3}{*}{$\mathrm{Yb}$} & $\mathrm{D}$ & 0.37 & 3.40 & 12.21 & 31.22 & 140.2 & \\
\hline & $\log _{(\text {Kex })}$ at $\beta=0.1$ & 4.79 & 4.75 & 4.40 & 4.35 & 4.47 & 4.55 \\
\hline & $\log _{(\text {Kex })}$ at $\beta=0.25$ & 5.44 & 5.40 & 5.06 & 5.00 & 5.12 & 5.21 \\
\hline
\end{tabular}

Organic phase: 1-5 mM CR4-Tz-DODGA in toluene / iso-octanol (90/10 v/v); Aqueous phase: $1 \mathrm{mM} \mathrm{Ln}\left(\mathrm{NO}_{3}\right)_{3}$ in $5 \mathrm{M} \mathrm{HNO}_{3}$. 


\subsubsection{Effect of nitric acid concentration}

Figure 3 represents the distribution coefficients and the selectivity results obtained for the extraction of $\mathrm{La}^{3+}, \mathrm{Eu}^{3+}$, and $\mathrm{Yb}^{3+}$ with $1 \mathrm{mM}$ CR4-Tz-DODGA while varying the concentration of nitric acid from 1 to $5 \mathrm{M}$. The presented data clearly shows the dependence of the distribution values and the selectivity factors on the concentration of the feed nitric acid. The results are in good agreement with the behavior observed in liquid-liquid extraction systems using neutral ligands (solvating agents). Generally, an increase in the feed nitric acid concentration leads to an increase in the distribution ratio values,[37] this is also the case in our study. The extraction of REEs increased with an increase in the nitric acid concentration up to $5 \mathrm{M}$ (Figure 4). At the above conditions, efficient extraction of LREEs where not observed, while extraction of HREE was favored at higher $\mathrm{HNO}_{3}$ concentration, indicating the possibility of selective extraction of HREE. By increasing the ligand concentration at $5 \mathrm{mM}$, it was possible to perform a mutual separation of REEs with an extraction efficiency value $24 \%$ for La, $83 \%$ for Eu and $99 \%$ for Yb (see supporting information Table S1).

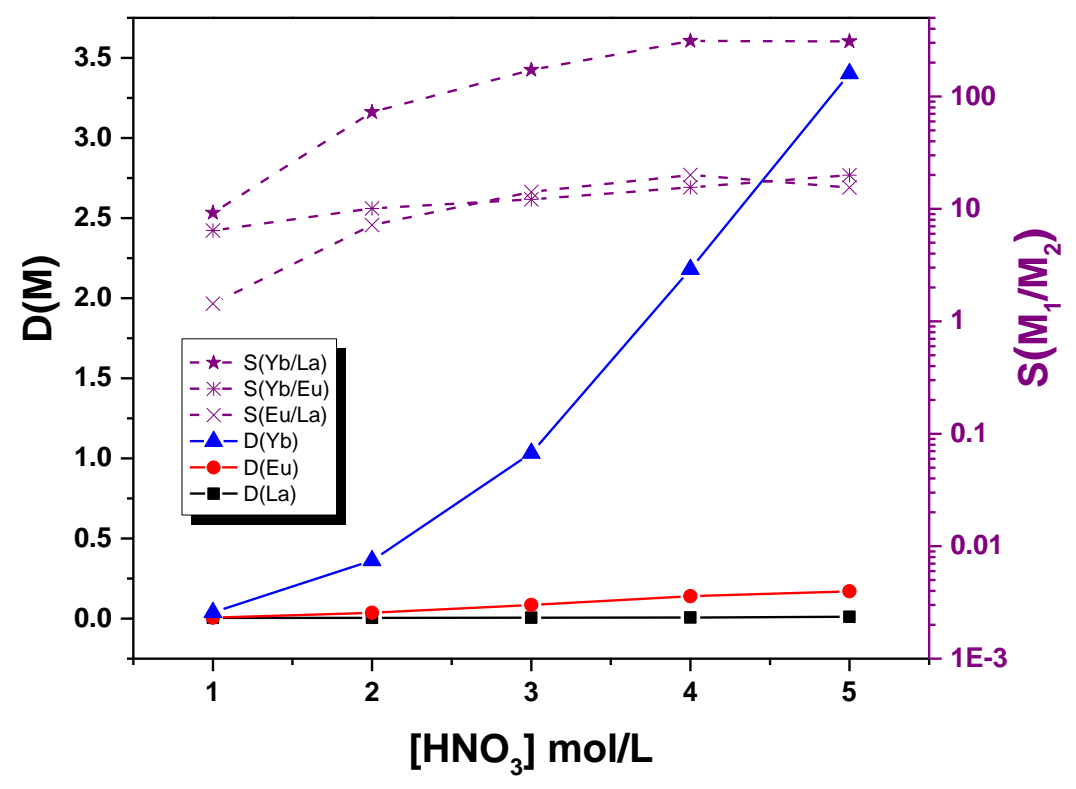

Figure 4: Effect of nitric acid concentration on the Distribution ratios and the selectivity factors of La(III), Eu(III), and Yb(III); Organic phase: $1 \mathrm{mM} \mathrm{CR4-Tz-DODGA} \mathrm{in} \mathrm{toluene} \mathrm{/} \mathrm{iso-octanol} \mathrm{(90/10} \mathrm{v/v);}$ Aqueous phase: $1 \mathrm{mM} \mathrm{Ln}\left(\mathrm{NO}_{3}\right)_{3}$ in 1 - $5 \mathrm{M} \mathrm{HNO}_{3}$.

However, an increase in the concentration of nitric acid from 1 to $5 \mathrm{M}$ resulted in an increase

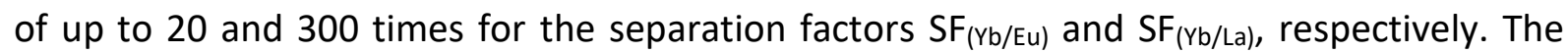
trend in extraction performance seems to be related to the charge density of the metal ion, showing a higher selectivity for the heavy rare earth elements (HREEs). This indicates that the rigidity of the macrocycle has a dramatic influence on the selectivity and complexation of metal ions, which largely depends on the ionic radius of the metal. 


\subsubsection{Effect of extractant concentration}

CR4-Tz-DODGA is considered to be a neutral complex extractant which forms complexes with the trivalent lanthanides through a mechanism which can be described using the following equation.[16]

$$
\mathrm{M}^{3+}+3 \mathrm{NO}_{3}^{-}+n \bar{L} \stackrel{\mathrm{K}_{\mathrm{ex}}}{\rightleftharpoons} \overline{M\left(\mathrm{NO}_{3}\right)_{3} \cdot L_{n}}
$$

In this equation, $M$ represents the REEs, $L$ represents the neutral extractant (CR4-Tz-DODGA), and $\overline{M\left(N_{3}\right)_{3} \cdot L_{n}}$ represents the metal-extractant complex in the organic phase. An overbar refers to a species in the organic phase and the absence of an overbar denotes an aqueous species.

Given that REEs extraction occurs primarily by a solvation mechanism, the metal M must be neutralized by $\mathrm{NO}_{3}{ }^{-}$. Acid extraction by the neutral compound was considered negligible.[38] To determine the stoichiometry of complexation $n$, the distribution ratios for the metal extraction at constant acidity were plotted as a function of extractant concentrations. The equilibrium concentration of extractant equals approximately its initial concentration, while in our calculations we considered the concentration of the ligand at equilibrium, $[L]_{\text {free, }}$ to obtain more accurate results. The $D$ values increased with increased ligand concentrations, which indicates that the CR4-Tz-DODGA is directly participating in complex formation.

The slope analysis method (Figure 5) was used to confirm the ratio of the ligand to the metal, straight lines with slopes of 2.13, 1.99 and 2.12 were found for $\mathrm{Yb}(\mathrm{III})$ and $\mathrm{Eu}(\mathrm{III})$ and $\mathrm{La}(\mathrm{III})$, respectively. This result suggests that the metal : ligand extraction complex stoichiometry for Ln (III) is $1: 2$, which is consistent with the solvent extraction studies reported in the literature.[16],[39],

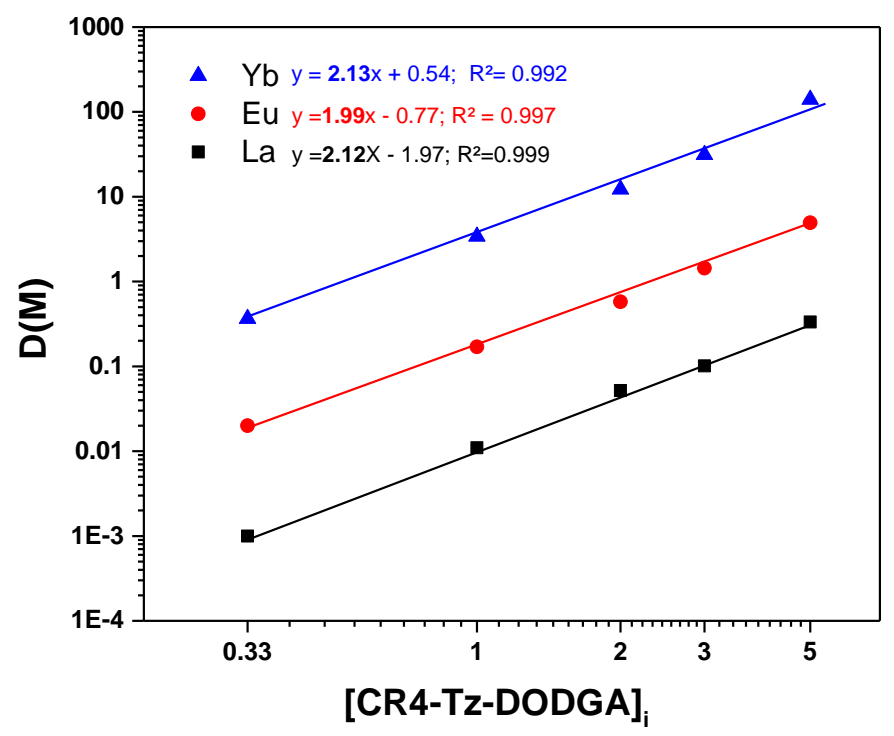

Figure 5: Effect of the extractant concentration on the distribution ratios of $L n(I I I)$; Organic phase: 0.33-5 mM CR4-Tz-DODGA in toluene / iso-octanol (90/10 v/v); Aqueous phase: $1 \mathrm{mM} \operatorname{Ln}\left(\mathrm{NO}_{3}\right)_{3} 5 \mathrm{M}$ in $\mathrm{HNO}_{3}$. 
Therefore the extraction constant, $\mathrm{K}_{\mathrm{ex}}$, can be represented as:

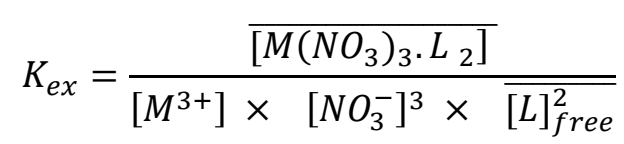

The distribution constant is represented in terms of the stability constant, $\beta_{\mathrm{i}}$, for nitrate complexes of $\mathrm{M}(\mathrm{III})$ as described in the following equation:

$$
D_{M}=\frac{\overline{\left[M\left(\mathrm{NO}_{3}\right)_{3} \cdot L_{2}\right]}}{\left[M^{3+}\right]\left(1+\sum \beta_{i}\left[N O_{3}^{-}\right]^{i}\right)}
$$

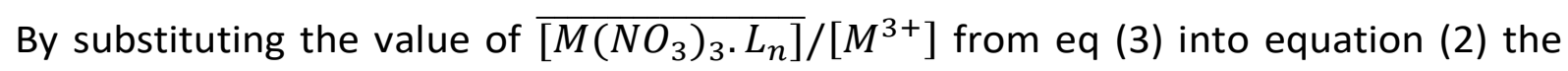
constant of extraction can be expressed as:

$$
K_{\text {ex }}=\frac{D_{M}\left(1+\sum \beta_{i}\left[\mathrm{NO}_{3}^{-}\right]^{i}\right)}{\left[\mathrm{NO}_{3}^{-}\right]^{3} \times \overline{[L]_{\text {free }}^{2}}}
$$

The $\beta_{i}$ values for the $\mathrm{NO}_{3}^{-}$complexation of $\mathrm{La}(\mathrm{III})$, and $\mathrm{Eu}(\mathrm{III})$ were obtained from the literature as $\left(\beta_{1}=1.29, \beta_{2}=0.36\right.$ for La) and $\left(\beta_{1}=1.86, \beta_{2}=0.43\right.$ for Eu $)$ at an ionic strength of 5.0.[40] $\beta_{1}$ of $\mathrm{Yb}$ was estimated between 0.1 and 0.25 due to the lack of information about $\mathrm{Yb}(\mathrm{III})$, and its corresponding LogK ex values are provided in range values corresponding to the estimated values of $\beta_{1}, 0.1$ and 0.25 (Table 1). From the distribution data, the apparent extraction equilibrium constants can be estimated. The average values of LogKex for La(III), Eu(III) and $\mathrm{Yb}(\mathrm{III})$ with the ligand are 3.19, 4.53 and 4.55-5.21, respectively (Table 1).

\subsubsection{Effect of temperature}

The effect of temperature on the extraction of lanthanides from $5 \mathrm{M} \mathrm{HNO}_{3}$ by $1 \mathrm{mM}$ of CR4Tz-DODGA in toluene / iso-octanol $(90 / 10 \mathrm{v} / \mathrm{v})$ was studied at a temperature range varying from 25 to $45{ }^{\circ} \mathrm{C}$. The distribution ratio for $\operatorname{Ln}(\mathrm{III})$ was found to decrease with increasing temperature, indicating the extraction process to be exothermic (Figure 5). The change in the enthalpy $(\Delta \mathrm{H})$ can be calculated using the Van't Hoff relationship where $\mathrm{R}$ is the gas constant:

$$
\log K_{e x}=-\frac{\Delta \mathrm{H}}{2.303 R} \cdot \frac{1}{T}+\frac{\Delta \mathrm{S}}{2.303 R}
$$

From the plot of log $\mathrm{K}_{\mathrm{ex}}$ versus $1 / \mathrm{T}$, straight lines were obtained as shown in Figure 6 . The $\Delta \mathrm{H}$ values were determined from the slopes of the straight lines (2.01 for $\mathrm{Yb}(\mathrm{III}), 1.79$ for $\mathrm{Eu}(\mathrm{III})$, and 1.57 for $\mathrm{La}(\mathrm{III}))$, while the entropy values were estimated to a first approximation from the intercept values (-1.25 for $\mathrm{Yb}(\mathrm{III}),-1.41$ for $\mathrm{Eu}(\mathrm{III})$, and -2.09 for $\mathrm{La}(\mathrm{III})$ ). 


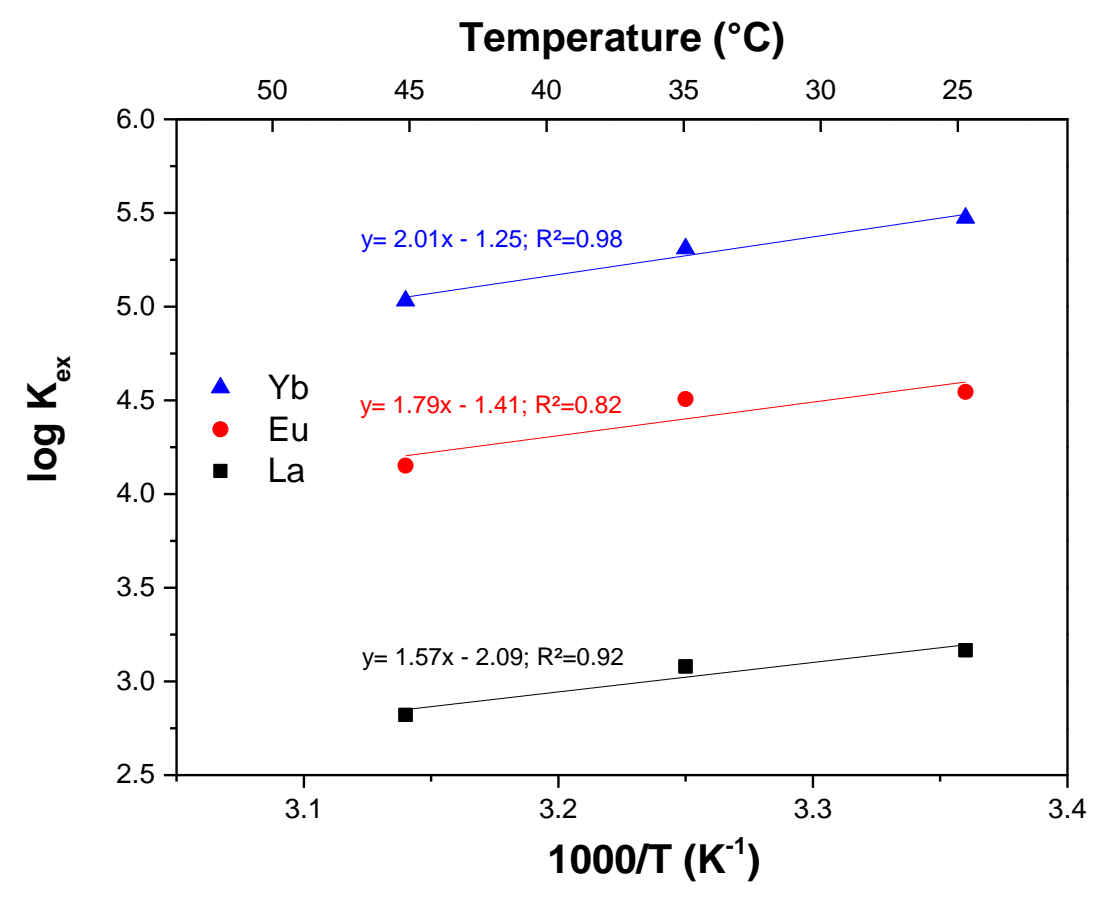

Figure 6: Effect of temperature on the apparent extraction equilibrium constants $\log K_{e x}$. Organic phase: $1 \mathrm{mM}$ CR4-Tz-DODGA in toluene / iso-octanol (90/10 v/v); Aqueous phase: $1 \mathrm{mM} \mathrm{Ln}\left(\mathrm{NO}_{3}\right)_{3}$ in $5 \mathrm{M}$ in $\mathrm{HNO}_{3}$.

In addition, the free energy change, $\Delta \mathrm{G}$, for the extraction at $298 \mathrm{~K}$ was obtained from Gibbs's Helmholtz equation.

$$
\Delta \mathrm{G}=\Delta \mathrm{H}-\mathrm{T} \Delta \mathrm{S}=-2.303 \mathrm{RT} \log \mathrm{K}
$$

The thermodynamic parameters, $\Delta \mathrm{H}, \Delta \mathrm{S}$, and $\Delta \mathrm{G}$ for the extraction of CR4-Tz-DODGA are summarized in Table 2. The results indicate that the extraction mechanism is similar for REEs regarding the entropy and enthalpy factors that can affect the extent of the metal ion extraction.

The overall enthalpy change depends on several contributing factors, such as, (i) dehydration of the metal ions $\left(\Delta \mathrm{H}_{1}\right)$, (ii) formation of neutral extracted species $\left(\Delta \mathrm{H}_{2}\right)$, and (iii) dissolution of the metal complex in the organic phase $\left(\Delta \mathrm{H}_{3}\right)$.

The negative $\Delta \mathrm{H}$ values suggest that the complexation between $\operatorname{Ln}(\mathrm{III})$ metal nitrate species and the neutral extractant molecule is exothermic (Table 2).

The negative entropy change $(-\Delta S)$ suggests the presence of a few water molecules in the primary coordination sphere of $\operatorname{Ln}(\mathrm{III})$. Interestingly, the change in the Gibbs free energy $(-\Delta G)$ follows the order: $\Delta G(Y b)>\Delta G(E u)>\Delta G(L a)$ which is the same order for the extraction efficiency. The negative values of $\Delta G$ at room temperature indicate that the extraction reactions are spontaneous. The more negative $\Delta G$ value for $Y b(I I I)$ indicates that the formation of the dissolved $\mathrm{Yb}(\mathrm{III})$ : CR4-Tz-DODGA complex is thermodynamically more favored in comparison to the dissolved complexes of Eu(III) and La(III).[41] 
Table 2: Thermodynamic parameters $(\Delta H, \Delta S$, and $\Delta G)$ for the extraction of $L a(I I I), E u(I I I)$ and $Y b(I I I)$ at $298 K$.

\begin{tabular}{cccccc}
\hline System & Slope & Intercept & $\Delta \mathbf{H}_{(\mathrm{kJ} / \mathrm{mol})}$ & $\Delta \mathbf{S}_{(\mathrm{J} / \mathrm{mol})}$ & $\Delta \mathbf{G}_{(\mathrm{kJ} / \mathrm{mol})}$ \\
\hline YbL2 & 2.01 & -1.25 & -38.45 & -24.03 & -31.29 \\
\hline EuL2 & 1.79 & -1.41 & -34.26 & -27.07 & -26.19 \\
\hline LaL2 & 1.57 & -2.09 & -30.10 & -39.94 & -18.19 \\
\hline
\end{tabular}

Organic phase: $1 \mathrm{mM} C R 4-T z-D O D G A$ in in toluene / iso-octanol (90/10 v/v); Aqueous phase: $1 \mathrm{mM} \mathrm{Ln}\left(\mathrm{NO}_{3}\right)_{3}$ in $5 \mathrm{M} \mathrm{HNO}_{3}$.

\subsubsection{Extraction Kinetics}

A study on the phase transfer kinetics indicated that equilibrium was attained quickly (Figure 7). The amount of Yb extracted increased rapidly, the values obtained after 15 minutes did not change after 60 minutes of shaking, a plateau is observed with a distribution ratio of approximately 98 . Thus, the extraction rate of Yb by CR4-Tz-DODGA was not a limiting factor in the extraction process.

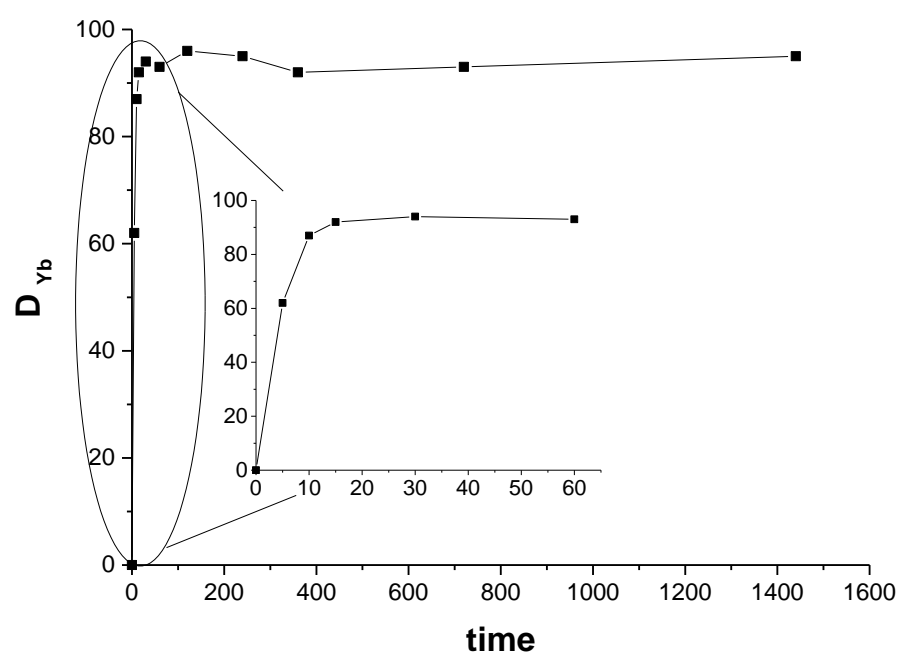

Figure 7: Distribution ratio of $Y b$ as a function of time.

Organic phase: $5 \mathrm{mM} C R 4-T z-D O D G A$ in toluene / iso-octanol (90/10 v/v);

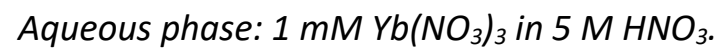

\subsection{Application to permanent magnets}

Considering the performances of CR4-Tz-DODGA in the extraction of REEs, the extractability of $\mathrm{Nd}$ and $\mathrm{Dy}$ over Fe and $\mathrm{B}$ from a simulated leaching solution from permanent magnets was studied. A new set of experiments was performed at $5 \mathrm{M}$ nitric acid with a total concentration of the metals fixed at $2 \mathrm{mM}$ in the following proportions: $70 \% \mathrm{Fe}, 10 \% \mathrm{Dy}, 10 \%$ $\mathrm{Nd}, 10 \% \mathrm{~B}$, to mimic a representative leaching solution of a $\mathrm{Nd} / \mathrm{Fe} / \mathrm{B} / \mathrm{Dy}$ magnet. The concentration of CR4-Tz-DODGA was varied from 1-3 mM, which corresponds to (M:L) ratios 
varying from 0.5-1.5. The data are presented in Table 3. The results show that the ligand selectively extracts Dy(III) with regards to the other cations. As shown in the previous study, the ligand was more selective towards the HREE with a Dy:Nd selectivity factor of $>45$.

These results demonstrate the potential use of CR4-Tz-DODGA towards the selective extraction of REEs with regards to competitive ions, especially iron - $\mathrm{SF}(\mathrm{Dy} / \mathrm{Fe})>1000$, which is the main competing ion in the nitric acid leaching solution.

Table 3: Distribution coefficients and separation factors for $\mathrm{Nd} / \mathrm{Dy} / \mathrm{Fe} / \mathrm{B}$ cations at $25^{\circ} \mathrm{C}$.

\begin{tabular}{rccccccc}
\hline [Lig.] & $\mathrm{D}(\mathrm{Fe})$ & $\mathrm{D}(\mathrm{B})$ & $\mathrm{D}(\mathrm{Nd})$ & $\mathrm{D}(\mathrm{Dy})$ & $\mathrm{SF}(\mathrm{Dy} / \mathrm{Nd})$ & $\mathrm{SF}(\mathrm{Dy} / \mathrm{B})$ & \multicolumn{2}{c}{$\mathrm{SF}(\mathrm{Nd} / \mathrm{B})$} \\
\hline $1 \mathrm{mM}$ & $<0.01$ & 0.04 & 0.01 & 2.1 & 210 & 52.5 & 0.25 \\
\hline $2 \mathrm{mM}$ & $<0.01$ & 0.02 & 0.10 & 6.8 & 68.0 & 340 & 5.0 \\
\hline $3 \mathrm{mM}$ & $<0.01$ & 0.03 & 0.25 & 11.7 & 46.8 & 390 & 8.3 \\
\hline
\end{tabular}

Organic phase: 1-3 mM CR4-Tz-DODGA in 90\% toluene/10\% iso-octanol ( $\mathrm{V} / \mathrm{V})$;

Aqueous phase: $2 \mathrm{mM}$ of cations $70 \% \mathrm{Fe} .10 \% \mathrm{Dy} .10 \% \mathrm{Nd}$. $10 \% \mathrm{~B}$ in $5 \mathrm{M} \mathrm{HNO}_{3}$.

\section{Conclusions}

A new ligand CR4-Tz-DODGA, corresponding to a tetra-methylcavitand functionalized at the upper rim with four 1,2,3-triazole-DGA binding units containing n-octyl groups, was synthesized with a satisfactory yield of $65 \%$ using a click reaction. Ligand-binding, at a concentration range from 1 to $5 \mathrm{mM}$, was investigated towards $1 \mathrm{mM}$ mixtures of three rare earth elements (REEs): $\mathrm{La}(\mathrm{III}), \mathrm{Eu}(\mathrm{III})$, and $\mathrm{Yb}(\mathrm{III})$. The distribution coefficients and selectivity factors increased with an increase in nitric acid concentration. At $5 \mathrm{M} \mathrm{HNO}_{3}$ with a $1 \mathrm{mM}$ ligand concentration, no real extraction of light REE (La and Eu) was observed but approximately $77 \%$ of $\mathrm{Yb}$ was extracted, indicating a selective extraction for heavy REEs. By increasing the ligand concentration to $5 \mathrm{mM}$, it was possible to perform a mutual separation of REEs (24\% of La, $83 \%$ of Eu and $99 \%$ of $\mathrm{Yb}$ are extracted). An extraction mechanism was proposed based on slope analysis and thermodynamic studies highlighting the differences between the LREEs and HREEs, which are linked to the extraction efficiency. These results allowed us to consider this ligand for the extraction of HREEs present in a solution mimicking a leaching solution of $\mathrm{Nd} / \mathrm{Dy} / \mathrm{Fe} / \mathrm{B}$ magnets. The selective extractability of Dy with regards to the other species in such solutions opens up interesting applications for this ligand.

\section{Acknowledgements}

We gratefully acknowledge the financial support for this project by the Lebanese University. CEDRE program. CNRSL (the National Council for Scientific Research. Lebanon). French CNRS. Montpellier University and the Labex Project CheMISyst (ANR-10-LABX-05-01). 


\section{References}

[1] C. Hurst, China's Rare Earth Elements Industry: What Can the West Learn?, Institute for the Analysis of Global Security Washington, 2010.

[2] Rare Earths: Global Industry, Markets \& Outlook, Roskill Information Services, 2015.

[3] K. Binnemans, P.T. Jones, B. Blanpain, T. Van Gerven, Y. Yang, A. Walton, M. Buchert, Recycling of rare earths: a critical review, Journal of Cleaner Production, 51 (2013) 1-22.

[4] K.L. Nash, G.J. Lumetta, Advanced separation techniques for nuclear fuel reprocessing and radioactive waste treatment, Woodhead Publishing Limited, 2011.

[5] J. Borrini, G. Bernier, S. Pellet-Rostaing, A. Favre-Reguillon, M. Lemaire, Separation of lanthanides(III) by inorganic nanofiltration membranes using a water soluble complexing agent, Journal of Membrane Science, 348 (2010) 41-46.

[6] S. Radhika, V. Nagaraju, B.N. Kumar, M.L. Kantam, B.R. Reddy, Solid-liquid extraction of Gd(III) and separation possibilities of rare earths from phosphoric acid solutions using Tulsion $\mathrm{CH}-93$ and Tulsion CH-90 resins, Journal of Rare Earths, 30 (2012) 1270-1275.

[7] R. Rahal, F. Annani, S. Pellet-Rostaing, G. Arrachart, S. Daniele, Surface modification of titanium oxide nanoparticles with chelating molecules: New recognition devices for controlling the selectivity towards lanthanides ionic separation, Separation and Purification Technology, 147 (2015) 220-226.

[8] L. Wang, X. Huang, Y. Yu, Z. Long, Kinetics of rare earth pre-loading with 2-ethylhexyl phosphoric acid mono 2-ethylhexyl ester HEH(EHP) using rare earth carbonates, Separation and Purification Technology, 122 (2014) 490-494.

[9] R. Turgis, G. Arrachart, V. Dubois, S. Dourdain, D. Virieux, S. Michel, S. Legeai, M. Lejeune, M. Draye, S. Pellet-Rostaing, Performances and mechanistic investigations of a triphosphine trioxide/ionic liquid system for rare earth extraction, Dalton Transactions, 45 (2016) 1259-1268.

[10] A. Rout, K. Binnemans, Liquid-liquid extraction of europium(iii) and other trivalent rare-earth ions using a non-fluorinated functionalized ionic liquid, Dalton Transactions, 43 (2014) 1862-1872.

[11] H. Stephan, K. Gloe, J. Beger, P. Muhl, Liquid-liquid extraction of metal ions with amido podands, Solvent Extraction and Ion Exchange, 9 (1991) 435-458.

[12] H. Stephan, K. Gloe, J. Beger, P. Muhl, Liquid-liquid extraction of metal ions with amido podands, Solvent Extraction and Ion Exchange, 9 (1991) 459-469.

[13] H.H. Dam, D.N. Reinhoudt, W. Verboom, Multicoordinate ligands for actinide/lanthanide separations, Chemical Society Reviews, 36 (2007) 367-377.

[14] Z. Kolarik, Complexation and separation of lanthanides(III) and actinides(III) by heterocyclic Ndonors in solutions, Chemical Reviews, 108 (2008) 4208-4252.

[15] S.A. Ansari, P. Pathak, P.K. Mohapatra, V.K. Manchanda, Aqueous Partitioning of Minor Actinides by Different Processes, Separation and Purification Reviews, 40 (2011) 43-76. 
[16] H. Huang, S. Ding, N. Liu, Y. Wu, D. Su, S. Huang, Extraction of trivalent americium and europium from nitric acid solution with a calixarene-based diglycolamide, Separation and Purification Technology, 123 (2014) 235-240.

[17] H.H. Dam, D.N. Reinhoudt, W. Verboom, Influence of the platform in multicoordinate ligands for actinide partitioning, New Journal of Chemistry, 31 (2007) 1620-1632.

[18] M. Iqbal, P.K. Mohapatra, S.A. Ansari, J. Huskens, W. Verboom, Preorganization of diglycolamides on the calix 4 arene platform and its effect on the extraction of $\mathrm{Am}(\mathrm{III}) / \mathrm{Eu}(\mathrm{III})$, Tetrahedron, 68 (2012) 7840-7847.

[19] A. Sengupta, P.K. Mohapatra, M. Iqbal, J. Huskens, W. Verboom, A highly efficient solvent system containing functionalized diglycolamides and an ionic liquid for americium recovery from radioactive wastes, Dalton Transactions, 41 (2012) 6970-6979.

[20] M.M. Garcia, R.T. Cabanas, A.T. Ochoa, A. Toscano, R. Cruz-Almanza, Supramolecular complexes between fullerene 60 - and 70 , and resorcinarene, Fullerene Science and Technology, 8 (2000) 475-482.

[21] F.C. Tucci, A.R. Renslo, D.M. Rudkevich, J. Rebek, Nanoscale container structures and their host - Guest properties, Angewandte Chemie-International Edition, 39 (2000) 1076-1079.

[22] K. Yonetake, T. Nakayama, M. Ueda, New liquid crystals based on calixarenes, Journal of Materials Chemistry, 11 (2001) 761-767.

[23] O. Haba, K. Haga, M. Ueda, O. Morikawa, H. Konishi, A new photoresist based on calix 4 resorcinarene dendrimer, Chemistry of Materials, 11 (1999) 427-432.

[24] C. Chamseddin, T. Jira, Chromatography Modeling Software Applicability for Non-Conventional Columns: a Case Study of Calixarene- and Resorcinarene-Bonded Stationary Phases, Chromatographia, 77 (2014) 1167-1183.

[25] K. Kobayashi, M. Yamanaka, Self-assembled capsules based on tetrafunctionalized calix 4 resorcinarene cavitands, Chemical Society Reviews, 44 (2015) 449-466.

[26] F. Davis, C.F.J. Faul, S.P.J. Higson, Calix 4 resorcinarene-surfactant complexes: formulation, structure and potential sensor applications, Soft Matter, 5 (2009) 2746-2751.

[27] B.A. Makwana, D.J. Vyas, K.D. Bhatt, V.K. Jain, Y.K. Agrawal, Highly stable antibacterial silver nanoparticles as selective fluorescent sensor for Fe3+ ions, Spectrochimica Acta Part a-Molecular and Biomolecular Spectroscopy, 134 (2015) 73-80.

[28] C. Ligeour, L. Dupin, A. Marra, G. Vergoten, A. Meyer, A. Dondoni, E. Souteyrand, J.-J. Vasseur, Y. Chevolot, F. Morvan, Synthesis of Galactoclusters by Metal-Free Thiol "Click Chemistry" and Their Binding Affinities for Pseudomonas aeruginosa Lectin LecA, European Journal of Organic Chemistry, (2014) 7621-7630.

[29] H.C. Kolb, M.G. Finn, K.B. Sharpless, Click chemistry: Diverse chemical function from a few good reactions, Angewandte Chemie-International Edition, 40 (2001) 2004-+.

[30] I. Billault, F. Pessel, A. Petit, R. Turgis, M.-C. Scherrmann, Investigation of the copper(I) catalysed azide-alkyne cycloaddition reactions (CuAAC) in molten PEG(2000), New Journal of Chemistry, 39 (2015) 1986-1995. 
[31] H.C. Kolb, K.B. Sharpless, The growing impact of click chemistry on drug discovery, Drug Discovery Today, 8 (2003) 1128-1137.

[32] R. Turgis, G. Arrachart, C. Delchet, C. Rey, Y. Barre, S. Pellet-Rostaing, Y. Guari, J. Larionova, A. Grandjean, An Original "Click and Bind" Approach for Immobilizing Copper Hexacyanoferrate Nanoparticles on Mesoporous Silica, Chemistry of Materials, 25 (2013) 4447-4453.

[33] K. Neibert, V. Gosein, A. Sharma, M. Khan, M.A. Whitehead, D. Maysinger, A. Kakkar, "Click" Dendrimers as Anti-inflammatory Agents: With Insights into Their Binding from Molecular Modeling Studies, Molecular Pharmaceutics, 10 (2013) 2502-2508.

[34] S. Taktak, R. Weissleder, L. Josephson, Electrode Chemistry Yields a Nanoparticle-Based NMR Sensor for Calcium, Langmuir, 24 (2008) 7596-7598.

[35] D.J. Cram, S. Karbach, H.E. Kim, C.B. Knobler, E.F. Maverick, J.L. Ericson, R.C. Helgeson, Hostguest complexation. 46. Cavitands as open molecular vessels form solvates, Journal of the American Chemical Society, 110 (1988) 2229-2237.

[36] J.R. Moran, S. Karbach, D.J. Cram, Cavitands: synthetic molecular vessels, Journal of the American Chemical Society, 104 (1982) 5826-5828.

[37] B. Mokili, C. Poitrenaud, Medium effect on the separation factor in liquid-liquid extraction. Application to the separation of trivalent lanthanide nitrates by tri-n-butylphosphate, Solvent Extraction and Ion Exchange, 15 (1997) 455-481.

[38] K.L. Nash, A review of the basic chemistry and recent developments in trivalent f-elements separations, Solvent Extraction and Ion Exchange, 11 (1993) 729-768.

[39] P.K. Mohapatra, M. Iqbal, D.R. Raut, J. Huskens, W. Verboom, Unusual transport behaviour of actinide ions with a novel calix 4 arene-tetra-diglycolamide (C4DGA) extractant as the carrier, Journal of Membrane Science, 411 (2012) 64-72.

[40] S. Andersson, K. Eberhardt, C. Ekberg, J.O. Liljenzin, M. Nilsson, G. Skarnemark, Determination of stability constants of lanthanide nitrate complex formation using a solvent extraction technique, Radiochimica Acta, 94 (2006) 469-474.

[41] S.A. Ansari, P.N. Pathak, M. Husain, A.K. Prasad, V.S. Parmar, V.K. Manchanda, Extraction of actinides using N,N,N " N '-tetraoctyl diglycolamide (TODGA): a thermodynamic study, Radiochimica Acta, 94 (2006) 307-312. 